\title{
Comparison of Methods for Extraction of Keratin from Waste Wool
}

\author{
Eleanor M. Brown*, Kalgi Pandya, Maryann M. Taylor, Cheng-Kung Liu \\ Biobased and Other Animal Co-Products Research Unit, Eastern Regional Research Center, Agricultural Research Service, \\ US Department of Agriculture, Wyndmoor, PA, USA \\ Email: *ellie.brown@ars.usda.gov
}

How to cite this paper: Brown, E.M., Pandya, K., Taylor, M.M. and Liu, C.-K. (2016) Comparison of Methods for Extraction of Keratin from Waste Wool. Agricultural Sciences, 7, 670-679.

http://dx.doi.org/10.4236/as.2016.710063

Received: September 16, 2016

Accepted: October 22, 2016

Published: October 25, 2016

Copyright $\odot 2016$ by authors and Scientific Research Publishing Inc. This work is licensed under the Creative Commons Attribution International License (CC BY 4.0). http://creativecommons.org/licenses/by/4.0/

\begin{abstract}
The U.S. sheep industry, more than 80,000 producers of 40 million pounds of raw wool per year, is an important component of the meat industry. New methods for the treatment of domestic wool with keratin isolated from the unmarketable fraction of wool, and functionalized for water, oil, or insect repellency are needed. As a first step in the process, we are evaluating the effectiveness of keratin solubilization via relatively benign methods that use thioglycolic acid, bisulfite or sulfide to reduce disulfide bonds, peracetic acid or percarbonate to oxidize disulfides, and urea/thiourea as hydrogen bond disrupters. The procedures are compared in terms of quality of soluble protein, cost effectiveness, potential for upscaling, environmental and operator safety. Successful completion of this project will provide the basis for commercial development of such methods, followed by functional modification of the soluble keratin, and its application to textiles.
\end{abstract}

\section{Keywords}

Waste Wool, Keratin Extraction, Economic Comparison

\section{Introduction}

The US sheep industry, a small but important component of the meat industry, consists of 80,000 producers of 5 million sheep and 27 million pounds of raw wool per year. Although domestic wool has properties that limit its acceptance and competitiveness when compared to imported wool, the military and many law enforcement agencies are required to use domestically raised and processed wool for their uniforms and other wool containing products. An enzymatically-modified wool, developed at this Center, in an earlier project has been evaluated by the US military for use in undergarments [1] [2]. Meeting additional preferences of military and general consumer markets for al- 
tered wool properties-flame resistance, navy whiteness, and oil and water repellencyrequires further research on the functional modification of woolen textiles and yarn.

Previous research from this laboratory has modified collagenous waste from the production of leather for utilization in leather finishing steps to improve the final product [3]-[6]. In a similar fashion, we propose to expand on the work of Gembeh et al. [7] and develop methods for modifying the wool protein, keratin, from the unmarketable fraction of domestic wool by adding characteristics such as water, oil, or insect repellency to the extracted protein and then incorporating the modified protein into wool textiles.

In contrast with collagen, where the fibrous proteins are distinct and separable, keratin is a heavily crosslinked network of proteinaceous material with variable composition. The recent publication by Deb-Choudhury et al. [8] is a comprehensive review of options for extracting keratins and keratin associated proteins from wool and hair. The past decade has seen an upsurge in research into utilization of waste keratin as a biotechnology resource. Having a soluble or at least semi-soluble substrate is essential for most protein modification processes, and the highly disulfide crosslinked structure of keratin presents a challenge. A variety of methods for preparing a soluble keratin fraction from human hair as well as from meat industry byproducts, mainly wool, hair, and feathers are available in the literature. The intent of this study is to evaluate some of these methods in the search for an effective, reasonably safe, environmentally responsible and cost effective method for preparing soluble keratin for future product development that would be expected to encourage domestic processing and open new markets for US wool.

\section{Experimental}

\subsection{Materials}

Wool fiber, 24.0 - 25.0 micron, scoured and combed, was supplied by Chargeurs Wool (USA) Jamestown, SC and analyzed for moisture, ash and residual lipid as described by Taylor et al. [9]. Reagent grade chemicals were used except where otherwise noted.

\subsection{Removal of Residual Lipid}

Wool fibers were cut into $\sim 1 / 4$ in lengths and treated by one of the following published procedures to remove residual lipid. 1) Washed for $2 \mathrm{~h}$ in a $0.1 \%$ solution of TWEEN 20 , rinsed with water, and vacuum filtered on Whatman \#2 paper [10];2) Immersed in a mixture of chloroform/methanol $(2: 1, \mathrm{v} / \mathrm{v})$ for $24 \mathrm{~h}$, and filtered as above [11]; 3$)$ Soxhlet extracted with petroleum ether for $6 \mathrm{~h}$ [12] or 4) Soxhlet extracted with hexane for $6 \mathrm{~h}$. After the extraction, fibers were air-dried, and stored under vacuum without heat overnight before weighing. Solvents were evaporated to dryness, and the residual lipid weighed.

\subsection{Analysis of Wool for Moisture, Ash, and Residual Lipid}

Moisture and ash were determined on $\sim 0.5 \mathrm{~g}$ samples of wool before and after hexane 
extraction as described by Taylor et al. [9]. For moisture determination, samples in tared weighing bottles were dried under vacuum at $50^{\circ} \mathrm{C}$ for $48 \mathrm{~h}$, then cooled in a desiccator and weighed. Dried samples from the moisture determination were transferred to porcelain dishes and ashed at $600^{\circ} \mathrm{C}$ in a muffle furnace for $2 \mathrm{~h}$, then cooled and weighed. Lipid determination for the wool prior to Soxhlet extraction with hexane was by chloroform extraction of wool that had been hydrolyzed in $6 \mathrm{M} \mathrm{HCl}$ [9]. For hexaneextracted wool, the lipid containing extraction solvent was transferred to weighed crystallizing dishes that were reweighed after the solvent was evaporated to dryness.

\subsection{Solubilization}

Initial solubilization experiments were carried out on $0.5 \mathrm{~g}$ to $2.0 \mathrm{~g}$ batches of extracted wool fibers. For the final comparison $1.0 \mathrm{~g}$ samples were used for oxidation and reduction methods not involving urea. The sample size for methods that used $5 \mathrm{M}$ to $8 \mathrm{M}$ urea was $0.5 \mathrm{~g}$, because of the difficulty and expense of using large quantities of urea. Vacuum filtration on qualitative filter paper removed any remaining fibers after initial steps in solubilization. Final separations of soluble and insoluble extracted fractions were by centrifugation at $15,000 \mathrm{~g}$ for $30 \mathrm{~min}$ at ambient temperature. Supernatant and solid fractions from centrifugation were dialyzed in 6000 - 8000 MWCO (molecular weight cut off) tubing over 3 days with 6 changes of deionized water, and then lyophilized. All procedures were performed at least three times.

\subsubsection{Oxidation-Peracetic Acid (PAA)}

The method of Sando et al. [13] for isolation of keratin from wool was adapted as follows. Fibers were oxidized overnight at $37^{\circ} \mathrm{C}$ and $180 \mathrm{rpm}$ in $2 \%$ peracetic acid, then filtered and washed with water. The oxidized fibers were then extracted $2 \times$ with 100 $\mathrm{mM}$ Tris-base $(\mathrm{pH} 10.5)$ at $37^{\circ} \mathrm{C}$ and $180 \mathrm{rpm}$ for $3 \mathrm{~h}$, and $1 \times$ with water. Extracts were pooled and adjusted to $\mathrm{pH} 4$ with $0.5 \mathrm{M} \mathrm{HCl}$ to precipitate protein. Precipitated protein was allowed to settle overnight. The liquid phase was decanted, and the precipitate was washed with $100 \mathrm{mM}$ Tris- $\mathrm{HCl} \mathrm{pH} 4$ and then redissolved in $100 \mathrm{mM}$ Tris-base, $\mathrm{pH}$ 7.5.

\subsubsection{Oxidation-Percarbonate (PCC)}

A second oxidation method was based on the leather related oxidative dehairing studies of Shi et al. [14] and Marmer and Dudley [15]. A 30\% solution of $\mathrm{NaOH}$ in water was prepared and allowed to cool overnight. Wool fibers were hydrated by soaking overnight in water. On the next day, excess water was removed by filtration, and the cooled $\mathrm{NaOH}$ solution was added at $3 \%$ on the weight of dry wool. After the wet wool and $\mathrm{NaOH}$ were thoroughly mixed, solid sodium percarbonate was added at $4.5 \%$ on the weight of dry wool. The mixture was stirred for 3 to $4 \mathrm{~h}$ until wool fibers were no longer visible.

\subsubsection{Reduction/Oxidation-Thioglycolate/Hydrogen Peroxide (TGA)}

The reduction/oxidation method of Hatakeyama et al. [10] for extracting keratin from 
human hair was adapted as follows. Wool fibers were suspended in $0.2 \mathrm{M}$ sodium thioglycolate, $\mathrm{pH} 12$, at a 50:1 vol/wt ratio in a stoppered flask. The mixture was stirred overnight at ambient temperature, $21^{\circ} \mathrm{C}-23^{\circ} \mathrm{C}$. On the next day, the mixture was diluted with an equal volume of deionized water, and the $\mathrm{pH}$ was reduced to 10.5 with 0.5 $\mathrm{M} \mathrm{HCl}$, and the mixture was centrifuged at $15,000 \mathrm{~g}$ for $30 \mathrm{~min}$. The supernatant was adjusted to $\mathrm{pH} 7$ with dilute $\mathrm{HCl}$ and oxidized with $0.25 \mathrm{ml} 3 \% \mathrm{H}_{2} \mathrm{O}_{2}$ per $\mathrm{ml}$ supernatant for $3 \mathrm{~h}$. The $\mathrm{pH}$ was then adjusted to 4 with $0.5 \mathrm{M} \mathrm{HCl}$ and a solid fraction was allowed to precipitate overnight.

\subsubsection{Denaturation/Reduction-Urea/2-Mercaptoethanol (UTM)}

The Shindai method developed by Nakamura et al. [11] for extraction of keratin from human hair was adapted as follows. Briefly, wool fibers $(0.5 \mathrm{~g})$ were incubated for 3 days at $50^{\circ} \mathrm{C}$ and $100 \mathrm{rpm}$ at $\mathrm{pH} 8.5 \mathrm{in} 125 \mathrm{ml}$ of $25 \mathrm{mM}$ Tris, $2.6 \mathrm{M}$ thiourea, $5 \mathrm{M}$ urea, and 5\% 2-mercaptoethanol. At the end of 3 days, the mixture still had a large fluffy component that was centrifuged out at $15,000 \mathrm{~g}$ for $30 \mathrm{~min}$.

\subsubsection{Denaturation/Reduction-Urea/ Metabisulfite (SMB)}

The method of Isarankura $\mathrm{Na}$ Ayutthaya et al. [16] for extracting keratin from chicken feather waste was adapted. Briefly, wool fibers $(0.5 \mathrm{~g})$ were incubated for $5 \mathrm{~h}$ at $65^{\circ} \mathrm{C}$, $120 \mathrm{rpm}$ in $35 \mathrm{ml}$ of a solution containing $8 \mathrm{M}$ urea, $0.25 \% \mathrm{SDS}$, and $2 \mathrm{~g}$ sodium metabisulfite.

\subsubsection{Reduction-Sulfide (SUL)}

The method of Feairheller et al. [17] for solubilization of cattle hair was adapted. Briefly, wool fibers ( $1 \mathrm{~g}$ ) were soaked in $150 \mathrm{ml}$ deionized water for $20 \mathrm{~min}$, then $1 \mathrm{~g}$ sodium sulfide was added for $5 \mathrm{~min}$, followed by $3.2 \mathrm{~g}$ calcium oxide (lime). The mixture was gently stirred for $48 \mathrm{~h}$.

\subsection{Electrophoresis}

Lyophilized samples ( 1.0 mg) were dissolved in electrophoresis buffer (1 mM EDTA, $2.5 \%$ SDS, $5 \% 2$-mercaptoethanol and $0.01 \%$ bromophenol blue) for analysis by SDSPAGE (polyacrylamide gel electrophoresis in sodium dodecyl sulfate). The samples were heated at $90^{\circ} \mathrm{C}$ for $15 \mathrm{~min}$. Separation was achieved on a PhastGel System (GE Life Sciences, Piscataway, NJ) using the standard protocol for protein on $20 \%$ homogenous gels. A broad range SDS-Standard (Bio-Rad, Hercules, CA) containing nine proteins ranging in size from 6500 to 200,000 Daltons was included as a control on each gel. Gels were stained with Coomassie Brilliant Blue R.

\subsection{Economic Analysis}

The solubilization methods were compared with respect to efficiency in terms of the number of operator steps and the overall length of time required. For a relative cost estimation, the prices per gram of wool, of chemicals other than dilute acids or bases were compared, and any requirement for additional heat was noted. Additional considera- 
tions were operator safety, and the probable ease of scaling the process up.

\section{Results and Discussion}

Wool that has been cleaned (scoured) for commercial processing into yarns and textiles, retains some residual lipid that must be removed prior to solubilizing the keratin [18]. There are nearly as many protocols for removal of residual lipid as there are researchers on the topic of soluble keratin. The aim of this research was to develop a reasonably benign, safe and cost effective procedure that could effectively clean the wool of any residual lipid. Intuitively, a surfactant wash such as that used for human hair [10] and wool [19] seemed like a good choice. However, when these wool fibers were treated with $0.1 \%$ TWEEN20, the result was a wool fiber clump that could not be washed free of surfactant. The chloroform/methanol treatment for human hair [11] was ineffective for wool fibers, which tended to form clumps that required milling prior to further processing. Soxhlet extraction of $1 / 4$ in. fibers with petroleum ether [12] for $6 \mathrm{~h}$ removed $\sim 3 \mathrm{mg}$ lipid per g wool and produced a sample easily used for further experiments. Soxhlet extraction with hexane, a solvent frequently used for lipid extractions that is somewhat less flammable than ether, proved equally effective, removing slightly more than $3 \mathrm{mg}$ lipid per $\mathrm{g}$ wool.

Results of triplicate analysis of this wool fiber sample before and after hexane extraction [9] are shown in Table 1. Crude protein $90.79 \% \pm 0.38 \%$ was determined on the hexane extracted wool and calculated from total nitrogen using a factor of 6.06, estimated from the amino acid analyses of Freddi et al. [20] and Jones [21].

\subsection{Solubilization}

With the exception of the peracetic acid oxidation and the urea/mercaptoethanol denaturation/reduction methods, wool fibers disappeared from the reaction vessel and were not retained on paper during the initial filtration. Both supernatant and solid fractions resulting from centrifugation were comprised of material that was extracted from the fibers with varying degrees of solubility under the final conditions. A comparison of the solubilization methods in terms of the weight of solubilized keratin per gram of wool fiber was hindered by the small size of the samples and electrostatic forces that caused protein to adhere to the lyophilizing flasks.

\subsection{Electrophoresis}

Electrophoresis was carried out on $20 \%$ homogeneous gels in anticipation that most of

Table 1. Analysis of wool.

\begin{tabular}{cccc}
\hline Sample & Moisture \% & Ash $^{\mathrm{a}} \%$ & Lipid $^{\mathrm{a}} \%$ \\
\hline Raw wool & $7.06 \pm 0.70$ & $0.82 \pm 0.30$ & $1.20 \pm 0.51^{\mathrm{b}}$ \\
Hexane extracted & $8.68 \pm 0.21$ & $1.48 \pm 0.17$ & $2.93 \pm 0.03^{\mathrm{c}}$ \\
\hline
\end{tabular}

${ }^{\mathrm{a}} \mathrm{On}$ a dry weight basis; ${ }^{\mathrm{b}}$ Determination for raw wool was by $\mathrm{HCl}$ hydrolysis followed by $\mathrm{CHCl}_{3}$ extraction; ${ }^{\mathrm{c}}$ Determined from the weight of lipid removed from wool by Soxhlet extraction with hexane. 
the soluble keratin would be hydrolyzed to the 5 to $25 \mathrm{~K}$ molecular weight range [22]. The methods employed in this work were milder, and produced a wider molecular weight range of keratin fragments. Not surprisingly, given the nonhomogeneous nature of wool protein, no single molecular weight fragment was observed. Peracetic acid (PAA) oxidation produced the largest soluble fragments with molecular weights $>60 \mathrm{~K}$, and no low molecular weight fragments that were retained on the gel (Figure 1, lanes 2 and 3). Percarbonate (PCC) oxidation produced fragments in the $50-200 \mathrm{~K}$ range (Figure 1, lanes 4 and 5). The TGA method that reduces the keratin with thioglycolic acid and then uses hydrogen peroxide to oxidize the solubilized protein produced fragments (Figure 1, lanes 6 and 7) across the entire $6 \mathrm{~K}$ to $200 \mathrm{~K}$ range, with most material in the $40-70 \mathrm{~K}$ range characteristic of intermediate filaments [23].

Two methods that rely primarily on protein denaturation gave distinctly different results. The SMB procedure, urea denaturation with reduction by sodium metabisulfite, produced mostly fragments with molecular weights less than $30 \mathrm{~K}$ (Figure 2, lanes 2 and 3). In contrast, urea/thiourea denaturation with 2-mercaptoethanol reduction (UTM) produced the sharpest bands in the $60 \mathrm{~K}-80 \mathrm{~K}$ MW range (Figure 2, lanes 4 and 5) as predicted by Deb-Choudhury et al. [8], and also a smear of small fragments in the $6 \mathrm{~K}$ to $14 \mathrm{~K}$ range. Reduction with sulfide (SUL) produced fragments across the detectable molecular weight range with distinct fractions, in the $66 \mathrm{~K}, 40-50 \mathrm{~K}$, and $<20$ $\mathrm{K}$ ranges (Figure 2, lanes 6 and 7). In all cases, the similarity in the gel patterns between supernatant and solid fractions from centrifugation suggests that fractions that are extracted under solubilizing conditions may not remain in solution when the conditions are changed.

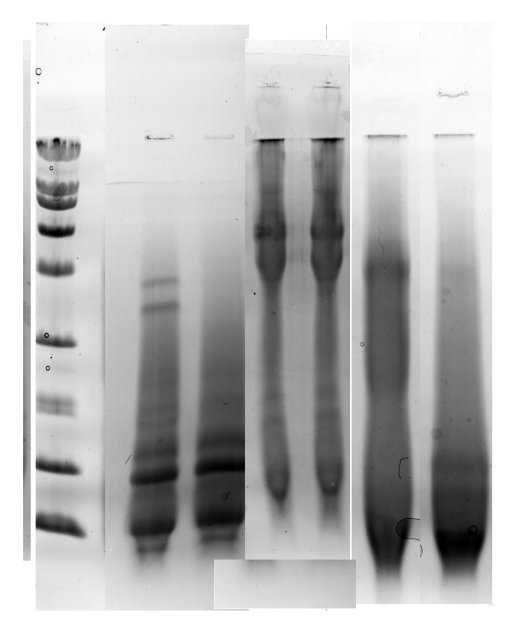

Figure 1. Lanes 1 and 8 represent the broad range standard containing 9 proteins with molecular weights at $200.0 \mathrm{~K}, 116.2 \mathrm{~K}, 97.4 \mathrm{~K}, 66.2 \mathrm{~K}, 45.0 \mathrm{~K}, 31.0$ $\mathrm{K}, 21.5 \mathrm{~K}, 14.4 \mathrm{~K}$, and $6.5 \mathrm{~K}$. Lanes 2 and 3 are solution and solid fractions of peracetic acid oxidized keratin. Lanes 4 and 5 are solution and solid fractions of percarbonate-oxidized keratin. Lane 6 is thioglycolate-reduced keratin, and lane 7 is thioglycolate/hydrogen peroxide reduced/oxidized keratin. The picture is a composite of separate SDS- PAGE experiments on $20 \%$ homogeneous gels for each treatment. 


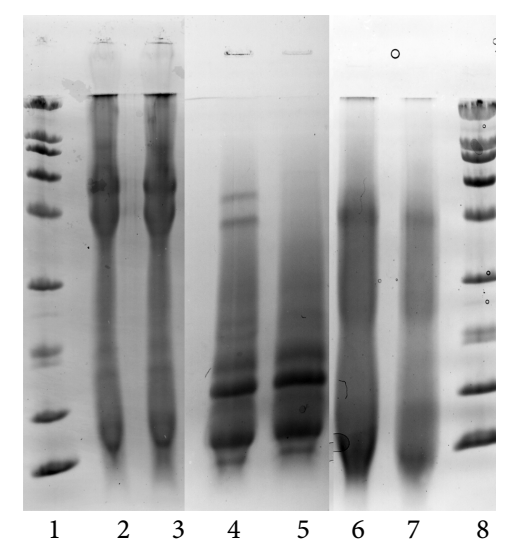

Figure 2. Lanes 1 and 8 represent the broad range standard containing 9 proteins with molecular weights from $200.0 \mathrm{~K}$ to $6.5 \mathrm{~K}$. Lanes 2 and 3 are solution and solid fractions of urea/thiourea denatured mercaptoethanol-reduced keratin. Lanes 4 and 5 are solution and solid fractions of urea/sodium metabisulfite reduced keratin. Lanes 6 and 7 are solution and solid fractions of sulfidereduced keratin. The picture is a composite of separate SDS-PAGE experiments on $20 \%$ homogeneous gels for each treatment.

\subsection{Economic Comparison}

Each of these methods is viable, in terms of cost of materials, energy input, and time at the research scale. When planning to scale the method up to the pilot plant or industrial level, differences become more important. The relative costs are compared in Table 2. In making this comparison, we have ignored the dialysis and lyophilization steps that are common to all of the methods and that could well be replaced by other ways of preparing for utilization of the soluble keratin. The comparison of costs of chemicals is based on the price from a single supplier of reagent grade chemicals for extraction of soluble protein from $1 \mathrm{~g}$ of wool. The methods are ranked $1-6$ on the assumption that when the process is scaled up, and the chemicals are technical grade, the relative prices will still be similar. Actual prices are not shown because they will vary over time and will depend on supplier availability. Overall, the input costs can be grouped in three sets. The percarbonate oxidation and sulfide reduction methods, which were originally developed for removing hair from cattle hide in preparation for leather tanning, have the lowest costs in terms of chemical and energy input. Thioglycolate reduction followed by hydrogen peroxide oxidation, and peracetic oxidation, both methods developed for solubilizing keratin, have intermediate costs with the major factors being storage of thioglycolate at $-80^{\circ} \mathrm{C}$ and the higher temperature required for the peracetic acid reaction. The highest input costs are for the urea/metabisulfite and urea/thiourea/ mercaptoethanol methods where chemical prices are an order of magnitude higher than for the other methods evaluated, and the requirement for an elevated temperature is also greater.

At the bench scale, each of these methods can be safely and effectively carried out. In judging whether or not it is practical to scale a process up to the pilot plant or industrial scale, factors in addition to the costs of chemicals and energy may become important. 
Table 2. Economic factors.

\begin{tabular}{lccccc}
\hline Method & Price $^{\mathrm{a}}$ & Days & Steps & Temp $^{\mathrm{b}}$ & Scale $^{\mathrm{c}}$ \\
\hline Oxidation/PCC & 1 & 1 & 3 & $\mathrm{RT}$ & ++ \\
Reduction/Sulfide & 2 & 2 & 3 & $\mathrm{RT}$ & ++ \\
Reduction-oxidation/TGA & 3 & 3 & 5 & $\mathrm{RT}$ & + \\
Oxidation/PAA & 4 & 3 & 5 & 37 & + \\
Denaturation-reduction/MBS & 5 & 1 & 1 & 65 & - \\
Denaturation-reduction/UTM & 6 & 3 & 3 & 50 & - \\
\hline
\end{tabular}

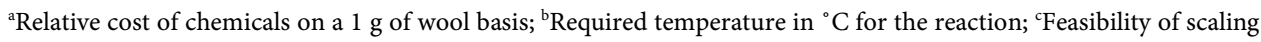
up the method, based on cost of reagents and energy input, as well as level of training needed for safe operation of the process, ++ means most feasible, -- means least feasible.

For example, working with small volumes of hydrogen peroxide for bench scale oxidation reactions is safe, but on a larger scale, the solid percarbonate, a typical component of nonchlorine laundry bleaches, would be a safer option for oxidation. In addition to safety, the ease of working with the reagents is a consideration. In this study, the ease of performing the procedure happened to decrease in parallel with increasing costs.

\section{Conclusion}

Six published methods for extracting keratin from meat animal byproducts and human hair were adapted for use with low quality wool fibers. Varying molecular weight fractions of keratin were obtained with the different methods, the urea/metabisulfite method produced mostly small fragments $6 \mathrm{~K}-10 \mathrm{~K} \mathrm{MW}$, while the oxidative methods produced fragments with molecular weights greater than $60 \mathrm{~K}$. Economic considerations such as the necessity of elevated thermal energy and the cost of materials were considered. Percarbonate oxidation and sulfide reduction, originally developed for removal of hair from cattle hide, performed comparably to methods intended for wool, human hair, or feathers. The data presented is expected to aid the scientist in deciding the method or the further adaption of which method is likely to produce the optimal component for the envisioned product.

\section{Acknowledgements}

The authors wish to thank Lorelie Bumanlag for her technical contributions. Mention of trade names or commercial products in this publication is solely for the purpose of providing specific information and does not imply recommendation or endorsement by the U.S. Department of Agriculture. USDA is an equal opportunity provider and employer.

\section{References}

[1] Cardamone, J.M. (2011) Expanding the Utility of the Agricultural Research Service (ARS) Process Bleaching. Textile Research Journal, 81, 1818-1827. http://dx.doi.org/10.1177/0040517511411969 
[2] Cardamone, J.M. and Yao, J. (2007) Methods of Improving Shrink-Resistance of Natural Fibers, Synthetic Fibers, or Mixtures Thereof, or Fabric or Yarn Composed of Natural Fibers, Synthetic Fibers, or Mixtures Thereof. US Patent No. 7090701.

[3] Taylor, M.M., Liu, C.K., Latona, N., Marmer, W.N. and Brown, E.M. (2002) Enzymatic Modification of Hydrolysis Products from Collagen Using a Microbial Transglutaminase. II. Preparation of Films. Journal of the American Leather Chemists Association, 97, 225234.

[4] Taylor, M.M., Bumanlag, L.P., Marmer, W.N. and Brown, E.M. (2006) Use of Enzymatically Modified Gelatin and Casein as Fillers in Leather Processing. Journal of the American Leather Chemists Association, 101, 169-178.

[5] Taylor, M.M., Bumanlag, L.P., Marmer, W.N. and Brown, E.M. (2009) Potential Application for Genipin-Modified Gelatin in Leather Processing. Journal of the American Leather Chemists Association, 104, 79-91.

[6] Taylor, M.M., Medina, M., Lee, J., Bumanlag, L.P., Latona, N.L., Brown, E.M. and Liu, C-K. (2013) Treatment of Hides with Tara-Modified Protein Products. Journal of the American Leather Chemists Association, 108, 438-444.

[7] Gembeh, S.V., Farrell Jr., H.M., Taylor, M.M., Brown, E.M. and Marmer, W.N. (2005) Application of Transglutaminase to Derivatize Proteins: 1. Studies on Soluble Proteins and Preliminary Results on Wool. Journal of the Science of Food and Agriculture, 85, 418-424. http://dx.doi.org/10.1002/jsfa.1999

[8] Deb-Choudhury S., Plowman, J.E. and Harland, D.P. (2016) Isolation and Analysis of Keratins and Keratin-Associated Proteins from Hair and Wool. Methods in Enzymology, 568, 279-301. http://dx.doi.org/10.1016/bs.mie.2015.07.018

[9] Taylor, M.M., Diefendorf, E.J., Phillips, J.G., Feairheller, S.H. and Bailey, D.G. (1986) Wet Process Technology I. Determination of Precision for Various Analytical Procedures. Journal of the American Leather Chemists Association, 81, 4-18.

[10] Hatakeyama, R., Tomita, Y. and Takigami, S. (2009) Preparation of Water Soluble Wool Keratin and Its Application for Human Hair. Transactions of the Materials Research Society of Japan, 34, 399-402. http://dx.doi.org/10.14723/tmrsj.34.399

[11] Nakamura, A., Arimoto, M., Takeuchi, K. and Fujii, T. (2002) A Rapid Extraction Procedure of Human Hair Proteins and Identification of Phosphorylated Species. Biological and Pharmaceutical Bulletin, 25, 569-572. http://dx.doi.org/10.1248/bpb.25.569

[12] Aluigi, A., Zoccola, M., Vineis, C., Tonin, C., Ferrero, F. and Canetti, M. (2007) Study on the Structure and Properties of Wool Keratin Regenerated from Formic Acid. International Journal of Biological Macromolecules, 41, 266-273. http://dx.doi.org/10.1016/j.ijbiomac.2007.03.002

[13] Sando, L., Kim, M., Colgrave, M.L., Ramshaw J.A.M., Werkmeister, J.A. and Elvin, C.M. (2010) Photochemical Crosslinking of Soluble Wool Keratins Produces a Mechanically Stable Biomaterial that Supports Cell Adhesion and Proliferation. Journal of Biomedical Materials Research - Part A, 95, 901-911. http://dx.doi.org/10.1002/jbm.a.32913

[14] Shi, B., Lu, X., Sun, D. and Cao, M. (2003) The Mechanism of Oxidative Unhairing Using Hydrogen Peroxide. Journal of the American Leather Chemists Association, 98, 185-192.

[15] Marmer, W.N. and Dudley, R.L. (2006) The Oxidative Degradation of Keratin (Wool and Bovine Hair). Journal of the American Leather Chemists Association, 101, 408-415.

[16] Isarankura Na Ayutthaya, S., Tanpichai, S. and Wootthikanokkhan, J. (2015) Keratin Extracted from Chicken Feather Waste: Extraction, Preparation, and Structural Characterization of the Keratin and Keratin/Biopolymer Films and Electrospuns. Journal of Polymers 
and the Environment, 23, 506-516. http://dx.doi.org/10.1007/s10924-015-0725-8

[17] Feairheller, S.H., Taylor, M.M., Windus, W., Filachione, E.M. and Naghski, J. (1972) Recovery and Analyses of Hair Proteins from Tannery Unhairing Wastes. Journal of Agricultural and Food Chemistry, 20, 668-670. http://dx.doi.org/10.1021/jf60181a033

[18] Anderson, C.A. and Leeder, J.D. (1966) Residual Lipid Contaminants in Processed Wool: Effect on Permanganate-Salt Shrinkproofing. Textile Research Journal, 36, 1016-1020. http://dx.doi.org/10.1177/004051756603601111

[19] Yamanaka, T., Iwashita, S. and Takigami, S. (2010) Preparation and Application of Soluble Wool Keratin. Transactions of the Materials Research Society of Japan, 35, 347-350. http://dx.doi.org/10.14723/tmrsj.35.347

[20] Freddi, G., Tsukada, M. and Shiozaki, H. (1999) Chemical Modification of Wool Fibers with Acid Anhydrides. Journal of Applied Polymer Science, 71, 1573-1579. http://dx.doi.org/10.1002/(SICI)1097-4628(19990307)71:10\%3C1573::AID-APP5\%3E3.3.C $\underline{\mathrm{O} ; 2-1}$

[21] Jones, L.N. (1975) The Isolation and Characterization of $\alpha$-Keratin Micro-Fibrils. Biochimica et Biophysica Acta, 412, 91-98. http://dx.doi.org/10.1016/0005-2795(75)90342-6

[22] Martin, J.J., Cardamone, J.M., Irwin, P.L. and Brown, E.M. (2011) Keratin Capped Silver Nanoparticles-Synthesis and Characterization of a Nanomaterial with Desirable Handling Properties. Colloids and Surfaces B: Biointerfaces, 88, 354-361.

http://dx.doi.org/10.1016/j.colsurfb.2011.07.013

[23] Jones, L.N., Simon, M., Watts, N.R., Booy, F.P., Steven, A.C. and Parry, D.A.D. (1997) Intermediate Filament Structure: Hard $\alpha$-Keratin. Biophysical Chemistry, 68, 83-93. http://dx.doi.org/10.1016/S0301-4622(97)00013-6

Submit or recommend next manuscript to SCIRP and we will provide best service for you:

Accepting pre-submission inquiries through Email, Facebook, LinkedIn, Twitter, etc. A wide selection of journals (inclusive of 9 subjects, more than 200 journals)

Providing 24-hour high-quality service

User-friendly online submission system

Fair and swift peer-review system

Efficient typesetting and proofreading procedure

Display of the result of downloads and visits, as well as the number of cited articles

Maximum dissemination of your research work

Submit your manuscript at: http://papersubmission.scirp.org/

Or contact as@scirp.org 